\title{
An investigation into the viability of LibraryThing for promotional and user engagement purposes in libraries
}

Article

Accepted Version

Richards, A. and Sen, B. (2013) An investigation into the viability of LibraryThing for promotional and user engagement purposes in libraries. Library Hi Tech, 31 (3). pp. 493-519. ISSN 0737-8831 doi: https://doi.org/10.1108/LHT-03-20130034 Available at https://centaur.reading.ac.uk/34368/

It is advisable to refer to the publisher's version if you intend to cite from the work. See Guidance on citing.

Published version at: http://www.emeraldinsight.com/journals. htm?issn=0737-

8831 \& volume $=31$ \&issue $=3$ \& articleid $=17097038$ \& show $=$ abstract

To link to this article DOI: http://dx.doi.org/10.1108/LHT-03-2013-0034

Publisher: Emerald

Publisher statement: This article is ( $)$ Emerald Group Publishing and permission has been granted for this version to appear here (http://centaur.reading.ac.uk/34368). Emerald does not grant permission for this article to be further copied/distributed or hosted elsewhere without the express permission from Emerald Group Publishing Limited.

All outputs in CentAUR are protected by Intellectual Property Rights law, including copyright law. Copyright and IPR is retained by the creators or other copyright holders. Terms and conditions for use of this material are defined in the End User Agreement. 


\section{www.reading.ac.uk/centaur}

\section{CentAUR}

Central Archive at the University of Reading

Reading's research outputs online 
Title: An investigation into the viability of LibraryThing for promotional and user engagement purposes in libraries

Authors: Anna Richards (University of Sheffield/University of Reading), Barbara Sen (University of Sheffield)

\section{$\underline{\text { Structured abstract }}$}

Purpose: LibraryThing is a Web 2.0 tool allowing users to catalogue books using data drawn from sources such as Amazon and the Library of Congress and has facilities such as tagging and interest groups. This study evaluates whether LibraryThing is a valuable tool for libraries to use for promotional and user engagement purposes.

Methodology: This study used a sequential mixed methods 3 phase design: (1) the identification of LibraryThing features for user engagement or promotional purposes, (2) exploratory semi-structured interviews (3) a questionnaire.

Findings: Several uses of LibraryThing for promotional and user engagement purposes were identified. The most popular reason libraries used LibraryThing was to promote the library or library stock, with most respondents using it specifically to highlight collections of books. Monitoring of patron usage was low and many respondents had not received any feedback. LibraryThing was commonly reported as being easy to use, remotely accessible, and having low cost, whilst its main drawbacks were the 200 book limit for free accounts, and it being a third-party site. The majority of respondents felt LibraryThing was a useful tool for libraries.

Practical implications: LibraryThing has most value as a promotional tool for libraries. Libraries should actively monitor patron usage of their LibraryThing account or request user feedback to ensure that LibraryThing provides a truly valuable service for their library.

Orginality :-There is little research on the value of LibraryThing for libraries, or librarians perceptions of LibraryThing as a Web 2.0 tool.

Acknowledgements: Funding for Anna Richards' Masters degree, during which this research was completed, was received via an AHRC Studentship. This article is based on a dissertation written as part of the requirements for the degree of Master of Arts in Librarianship at the University of Sheffield 2012.

Published article DOI: $\underline{\text { 10.1108/LHT-03-2013-0034 }}$

'This article is (c) Emerald Group Publishing and permission has been granted for this version to appear here (http://centaur.reading.ac.uk/). Emerald does not grant permission for this article to be further copied/distributed or hosted elsewhere without the express permission from Emerald Group Publishing Limited.' 


\section{Introduction [1]}

The use of Web 2.0 tools and websites in libraries is a topic which has generated much discussion. With many different tools to choose from it is necessary to ensure that those selected are worth the time invested in them. This study investigates one such tool, LibraryThing, outlining ways in which it could be used by libraries, and evaluating its overall value for libraries.

LibraryThing is a website which allows users to catalogue their own books and connect to other users through these books (LibraryThing, n.d.-a). Users search for a book they own and LibraryThing uses data from various sources, including Amazon and the Library of Congress, to provide records which users then personalise with tags, ratings and reviews (LibraryThing, n.d.-b). It also provides recommendations using a number of different methods and allows users to create interest groups through which they can communicate (LibraryThing, n.d.-b). This book and reading orientated website provides a ready audience for libraries. The LibraryThing team work with libraries through their LibraryThing for Libraries and LibraryThing Anywhere developments. LibraryThing for Libraries uses LibraryThing book data to add reviews, and tags to a library Online Public Access Catalogue (OPAC), along with other features, and LibraryThing Anywhere creates a mobile compatible version of an OPAC (LibraryThing, n.d.-c). The focus of this paper is on the features provided to website users, and on the ways in which libraries can use these features to promote their current services and engage with users.

\subsection{Aims and objectives}

The aim of this study is to evaluate the usefulness of LibraryThing for promotion and user engagement purposes for libraries. We investigate the different ways that LibraryThing can be used by libraries, and explore the attitudes of librarians who use it professionally. The objectives are to:

1. Identify the ways in which LibraryThing can be used by libraries to promote services or engage with users.

2. Identify how libraries are currently using LibraryThing and understand how useful LibraryThing is to librarians.

3. Evaluate the overall value of LibraryThing for libraries.

\section{Related Literature}

This review of the literature gives a general overview of Web 2.0 use in libraries in order to provide context for this investigation before focusing on libraries use of LibraryThing. Other websites which provide similar services, namely Goodreads and Shelfari, are discussed to provide a point of comparison.

'This article is (c) Emerald Group Publishing and permission has been granted for this version to appear here (http://centaur.reading.ac.uk/). Emerald does not grant permission for this article to be further copied/distributed or hosted elsewhere without the express permission from Emerald Group Publishing Limited.' 


\subsection{Web 2.0 and libraries}

O'Reilly (2005) described Web 2.0 as an interactive way of using the web, where users are encouraged to add content and interact with each other, which can be used to improve a service. There are several advantages to using Web 2.0 tools within library services. Stuart (2010, in Tripathi \& Kumar, 2010) argues that Web 2.0 tools help to bridge the gap between libraries and their users, increasing communication. Buigues-Garcia and Gimenez- Charnet (2012) argue that they allow the library to expand beyond the physical library building, with Chua and Goh (2010) arguing that increased communication leads to greater collaboration between librarians and users. Web 2.0 tools can encourage users to become more actively involved in library activities (Farkas, 2007 in Tripathi \& Kumar, 2010) by, for example, submitting reviews of library resources. Web 2.0 tools have also increased the ways that users can provide feedback to libraries and thus help library staff to improve the services (Mahmood \& Richardson Jr., 2011).

\subsubsection{Specific Web 2.0 tools used by libraries}

Chua and Goh (2010) found that the most popular Web 2.0 tools used in both public and academic libraries in North America, Asia and Europe were blogs, RSS feeds and instant messaging services, with social networks, wikis and the use of tagging falling behind. In studies of academic libraries only, instant messaging is found to be popular, along with RSS feeds and blogs (Harinarayana \& Raju, 2010; Kim \& Abbas, 2010; Mahmood \& Richardson Jr., 2011; Nesta and Mi, 2011; Pacheco, Kuhn \& Grant, 2010; Tripathi \& Kumar, 2010). Conversely, library use of wikis, podcasts and vodcasts,[2] and tagging facilities has been found to be low (Harinarayana \& Raju, 2010; Kim \& Abbas, 2010; Tripathi \& Kumar, 2010).

Han and Liu (2010) studied Web 2.0 use in Chinese university libraries. Of the universities studied, $71 \%$ had new generation OPACS which included features such as similar item suggestions and user ratings of items. Han and Liu (2010) found that RSS feeds were the second most popular tool, with blogs, instant messaging, social networking sites, and wikis not being very popular. Nesta and Mi (2011) also found that next generation catalogues were the most popular 'Web 2.0' tool in Hong Kong. The only other study that mentions this feature is Mahmood and Richardson Jr. (2011), who claim that some of the libraries in their study offered tagging in their OPACs.

More recent studies show a change in library Web 2.0 use. Mahmood and Richardson Jr. (2011) found that social networking sites were quite popular in academic libraries, whereas older studies found low usage (Chua \& Goh, 2010; Han \& Liu, 2010; Harinarayana \& Raju, 2010; Kim \& Abbas, 2010; Nesta \& Mi, 2011; Xu, Ouyang, \& Chu, 2009). Buigues-Garcia and Gimenez-Chornet $(2012$, p.10) stated that the most popular Web 2.0 tool used by national libraries was Facebook, with "RSS feeds, virtual or digital libraries, [and] Twitter" following. Cragg's (2010) study of business libraries found similar findings to academic libraries with blogs being the most popular tool. Conversely, the second most popular tool was microblogging on Twitter and the least popular were instant messaging and start pages, showing that there is a different pattern of use across different library sectors.

'This article is ( $)$ Emerald Group Publishing and permission has been granted for this version to appear here (http://centaur.reading.ac.uk/). Emerald does not grant permission for this article to be further copied/distributed or hosted elsewhere without the express permission from Emerald Group Publishing Limited.' 
The most common way in which the above tools are utilized is to provide news to users (Chua \& Goh, 2010; Cragg, 2010; Mahmood \& Richardson Jr., 2011; Tripathi \& Kumar, 2010). Both blogs and social networking sites are used as a user engagement and communication tool, allowing libraries to discuss topics of interest to users or to share media easily (Chua \& Goh, 2010; Mahmood \& Richardson Jr., 2011). Instant messaging is used to provide reference or enquiry services (Chua \& Goh, 2010; Cragg, 2010; Tripathi \& Kumar, 2010), with one study finding libraries using it specifically to provide homework help for students (Chua \& Goh, 2010).

Often libraries use Web 2.0 tools to provide study and library guides, or study resources, for students, including using wikis, podcasts or vodcasts, and video and audio sharing sites (Chua \& Goh, 2010; Mahmood \& Richardson Jr., 2011; Tripathi \& Kumar, 2010). Wikis are also used internally by libraries, for example, to share committee minutes (Cragg, 2010; Mahmood \& Richardson Jr., 2011). Anttiroiko and Savolainen (2011) found that instant messenger services, RSS feeds and Twitter were used to communicate with users quickly, with instant messaging services being specifically used for reference services. Blogs, wikis, Youtube and Flickr were used for content sharing, whilst social networking sites were used to provide news to users (Anttiroiko \& Savolainen, 2011). So Web 2.0 tools are used both as a

promotional tool by libraries and as a communication tool, and a way for libraries to provide new services or resources. Thus it is appropriate to examine how LibraryThing can be used for promotional or user engagement purposes, since this is how libraries are generally using Web 2.0 tools.

\subsubsection{Assessing the relevance of Web 2.0 tools.}

Millar (2010) identifies the need to be evaluative of any new ventures made by an institution when using a new Web 2.0 application. The tools used need to support users' needs, and the objectives of the institution (Millar, 2010). The advantages should be balanced against costs in regards to staff training, time and direct costs incurred (Millar, 2010). Tripathi and Kumar (2010) and Koltay (2010) argue that Web 2.0 tools should be used only if they are relevant and add value. Kim and Abbas (2010) and Nesta and Mi (2011) found that not many library users used the Web 2.0 tools implemented by libraries, suggesting a need to ascertain a tool's usefulness by users before investing. Nesta and Mi (2011) are particularly critical of the lack of user engagement engendered by Web 2.0 library initiatives and the lack of critical evaluation of Web 2.0 tools undertaken by libraries before they begin using them.

This need to be evaluative of Web 2.0 tools before using them is why this study considers not only how LibraryThing could be used but also attempts to evaluate whether the value it adds is worth the investment. Within both business and library literature there are discussions about measuring the Return on Investment (ROI) of Web 2.0 use (e.g., Fichter \& Wisniewski, 2008; Nair, 2011; Romero, 2011; Solis, 2011). Although it is beyond the scope of this study to discuss methods of assessing ROI in social media some questions regarding monitoring patron usage and feedback received will be addressed. These will not only bring to light any knowledge that libraries have about the popularity of LibraryThing but also whether libraries are attempting to evaluate their own use of Web 2.0 tools.

'This article is $\odot$ Emerald Group Publishing and permission has been granted for this version to appear here (http://centaur.reading.ac.uk/). Emerald does not grant permission for this article to be further copied/distributed or hosted elsewhere without the express permission from Emerald Group Publishing Limited.' 


\subsection{LibraryThing in the library literature}

Researchers have used LibraryThing in evaluations of tagging for indexing and their suitability as additions to library OPACs (Bates \& Rowley, 2011; Lawson, 2009; Lu, Park \& Hu, 2010; Rolla, 2009). Additionally, the creation of folksonomies has been linked to information literacy competencies and LibraryThing tags (Abdulhadi, Clough, \& Sen, 2012). The LibraryThing for Libraries application has also gained some attention as more libraries implement it (Blumenstein, 2007; Sheehan, 2007; Westcott, Chappell, \& Lebel, 2009), with some researchers focusing on tagging (Mendes, Quinonez-Skinner \& Skaggs, 2009; Webb \& Nero, 2009) and others looking at the recommender system element (Wakeling, Clough, \& Sen, 2012).

Wright and Bass (2010) encourage librarians to use LibraryThing, and other book based social networking sites, since this is where library users are. Eesiem (2007) and LibraryBug (2008) also feel that LibraryThing would be a good way to connect the library to its users, increasing the library's online presence. One of the most basic uses of LibraryThing by libraries is as a library catalogue, with small libraries, such as the Islington Mill Art Reference Library using it in such a way (Manchester Lit List, 2010). Such a use of LibraryThing is suggested by the LibraryThing team (LibraryThing, n.d.-d) and by librarian bloggers (O’Neill, 2009, Secret Library Island, 2010, Yellin, 2011), although as De La Cruz (2011) highlights, the lack of circulation statistics are a drawback to using LibraryThing in this way.

Harris (2006) suggests adapting LibraryThing functionality, so that students can review books they read in order to help teachers assess their reader development. Similarly, McMorland, Tolnay and Vick (2010), in a discussion of a public library initiative to help high school students with a specific assignment, mention that a LibraryThing account was created in which potentially useful books were assigned tags. A tag cloud was created using a LibraryThing widget and was added to the project's website (McMorland et al., 2010) [3]. These projects are examples of how LibraryThing can be used to support wider library activities.

Libraries can create specific collections on LibraryThing, highlighting books related to an event or to create a 'recommended list' for library members (LibraryThing, 2006; Rethlefsen, 2007; Steiner, 2008). For example, at the University of South Dakota the academic liaison librarians use LibraryThing to highlight bestsellers in their collection (De Jager-Loftus, 2009) whilst the library at Mukawongo used it to promote staff recommendations (Mukcomlibrary, 2011). Similarly, Steiner (2008) argues you can use it to promote new stock. It can be used to promote larger book collections; the Noble Neighborhood [sic] Library has created separate LibraryThing accounts for books in the mystery, horror and science fiction genres (Rethlefsen, 2007). It has been suggested that LibraryThing could be helpful for library book clubs. Starr (2008) mentions using it to create a list of books for a book club using the various recommendations LibraryThing provides, whilst Hastings (2009) argues that LibraryThing's 'Common Knowledge' section could provide additional information about books which may be useful for book discussions [4]. The Groups feature could also host online book clubs, as Lincoln College Library (23 Things Oxford, 2010) and St. Margaret's School Library have done (Eesiem, 2007).

'This article is ( $)$ Emerald Group Publishing and permission has been granted for this version to appear here (http://centaur.reading.ac.uk/). Emerald does not grant permission for this article to be further copied/distributed or hosted elsewhere without the express permission from Emerald Group Publishing Limited.' 
Another useful feature is using the tags to create sub-collections within the wider collection, helping users to find exactly what they need and illuminating the themes within the text, as done by the Carl A. Pescosolido Library (Rethlefsen, 2007). Libraries could then add a widget to their website or blog to bring these collections to the attention of their users, as was done by McMorland et al. (2010) in their project, and is suggested in many library blogs (e.g., 23 Things Oxford, 2010; O’Neill, 2009; Yellin, 2011) and by the LibraryThing team (LibraryThing, 2006; n.d.-d). Libraries could also encourage users to subscribe to the RSS feed for new additions to the account in order to bring the information to the user (23 Things Oxford, 2010; Hastings, 2009; Nuffield College Library, 2010; Rethlefsen, 2007; Vere Harmsworth Library, 2007; Wyatt, 2007)

Rethlefsen (2007), Rapp (2011) and Wyatt (2007) suggest that LibraryThing could be used by librarians to recommend new books for readers. Both Rapp (2011) and Abby Blachly (Ishizuka, 2006), an employee of LibraryThing, suggest the recommendations could be used for readers' advisory sessions. Librarians could consult the reviews given by LibraryThing members to help them judge the merit of a particular title (Rethlefsen, 2007) and librarians could write reviews of books in their collection (LibraryBug, 2008; Steiner, 2008). There are examples of librarians creating personal accounts, tagging items, and writing comments on LibraryThing, using it as a tool to help them recommend books for others (Wyatt, 2007). Librarians at Boise State University use LibraryThing internally to organise and track books requested by faculty (Kozel-Gains \& Stoddart, 2009). They liked LibraryThing because it was easy to use, could be personalised and provided "tagging functionality and comments fields" (Kozel-Gains \& Stoddart, 2009, p. 137). Both Steiner (2008) and the LibraryThing team (LibraryThing, n.d.-d) also suggest that a library could use the LibraryThing Local feature, where local book related events are posted, to publicise events that the library is holding, and Tay (2010) argues that libraries should at least monitor their listing in LibraryThing Local to ensure the information provided is correct.

Not all discussion of library use of LibraryThing has been positive. Feuille-blanche (2011) felt that users would be unlikely to go to another website to see new acquisitions, a concern shared by Murphy (2010). Seshat Scribe (2010) felt it held little value for academic libraries, though they did concede that it may be valuable for smaller libraries, whilst Birkwood (2011) thought that the global search facilities were not very good. Murphy (2010) was the most critical of the value of LibraryThing for libraries, expressing concern over the fact that LibraryThing is a third-party website, which could lead to security issues and a lack of authority, since it would not be part of the library brand. This shows that not all librarians are convinced of the value of LibraryThing, though this discussion was only conducted through personal blogs and not as a result of an in-depth analysis.

This shows that, although there is information regarding the use of LibraryThing by libraries in the literature, no thorough study has been conducted in to the true value of LibraryThing to libraries.

'This article is ( $)$ Emerald Group Publishing and permission has been granted for this version to appear here (http://centaur.reading.ac.uk/). Emerald does not grant permission for this article to be further copied/distributed or hosted elsewhere without the express permission from Emerald Group Publishing Limited.' 


\subsection{Other social reading sites}

There are other websites similar to LibraryThing. Goodreads has many similar features. You can add books and rate and review them, book pages include a summary, and there is the ability to search by genre from a book page as well (O'Leary, 2012; Goodreads Inc., 2012a). It is very socially oriented (Jeffries, 2008), with quizzes, member generated lists and reviews prominently displayed on a book page (Goodreads Inc., 2012a; O'Leary, 2012). It also has a Community space which is similar to LibraryThing's Group feature and members can post blog updates or messages on their home pages (O'Leary, 2012). It provides recommendations based on book ratings in your collection and on which genres interested you (Goodreads Inc., 2012b; O'Leary, 2012). It also provides recommendations on an individual book page which are generated automatically on a 'Readers also enjoyed' principle (Goodreads Inc., 2012a; O'Leary, 2012). Additionally, there are links to videos relating to the book you are viewing (Jeffries, 2008). Unlike LibraryThing it is completely free but there are advertisements on book pages (Jeffries, 2008; O'Leary, 2012). Tagging also plays less of role, with no tags appearing on a book page unlike on LibraryThing (Goodreads Inc., 2012a). In terms of library use, Rapp (2011) mentions that some libraries have used Goodreads to host online book clubs and Koppenhaver (2011) uses it personally to provide library patrons with book reviews, handing out 'business cards' with his Goodreads account name whilst working in the library. In this way he develops relationships with patrons who can interact with him online as well as at the library (Koppenhaver, 2011). Wyatt (2007) also mentions that it can used to help librarians with readers' advisory, similar to the way that LibraryThing can, due to its reviews and the ability for librarians to track and rate their own reading.

Shelfari is owned by Amazon and the price of buying the book through Amazon is displayed on the book page and there are also advertisements, which may deter some libraries (Shelfari, 2012a). On a book's page there is a synopsis, character and location lists and suggestions of themes present in the book, helpful for book clubs (Shelfari, 2012a). Recommendations are provided, based on Amazon purchase data (Shelfari, 2012a). The only obviously community generated recommendations are generated by asking other Shelfari members whether you should read a book (Jeffries, 2008) but there are community groups for members (Shelfari, $2012 b)$. There is a widget that could be added to a blog or website, which, like LibraryThing's widget, could highlight new stock or some other collection of books held by the library (Jeffries, 2008). As with LibraryThing and Goodreads, Rapp (2011) and Wyatt (2007) suggest that Shelfari could help with readers' advisory recommendations and at Jaypee University of Information Technology's library Shefari is used to highlight new additions to the library, grouped according to the course they relate to (Ram, Anbu K, \& Kataria, 2011).

Jeffries (2008), who compares all of the above social media sites, concludes that LibraryThing is of the most use to libraries and the fact that there is much more discussion of use of LibraryThing in the literature suggests that LibraryThing is the website of choice for libraries. The lack of advertisements on LibraryThing compared to Goodreads and Shelfari may also be a contributing factor for libraries.

'This article is ( $)$ Emerald Group Publishing and permission has been granted for this version to appear here (http://centaur.reading.ac.uk/). Emerald does not grant permission for this article to be further copied/distributed or hosted elsewhere without the express permission from Emerald Group Publishing Limited.' 


\section{Methodology}

This study used a sequential mixed design (Teddlie and Tashakkori, 2009). Using Morse's (2003) notation system this study is qual $\rightarrow$ QUAN, with the quantitative element being the main data collection method (Figure 1).

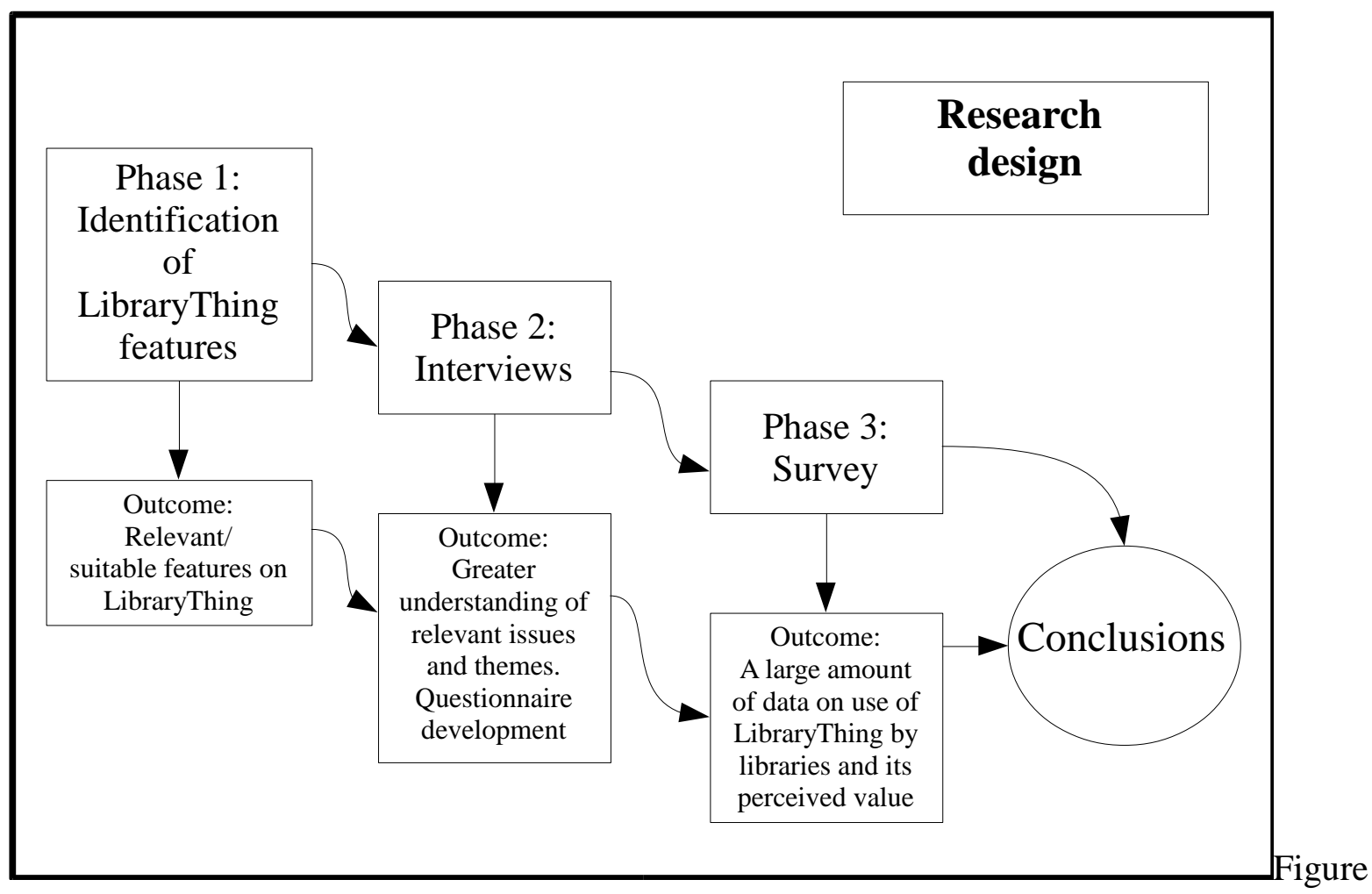

1: The research design

Phase 1 identifies features of use on LibraryThing for promotional and user engagement purposes, utilising data from the literature review and the researcher's knowledge of LibraryThing. Phase 2 of the study consisted of several interviews, which helped in understanding issues relating to library use of LibraryThing and informed the design of the questionnaire. Phase 3, the questionnaire, was sent electronically to libraries with a LibraryThing profile to gain insight into the attitudes of librarians to LibraryThing and their reasons for using it.

\subsection{Identifying organisational LibraryThing accounts}

In order to conduct the research it was necessary to identify libraries that use LibraryThing. There is no way of searching or browsing lists of library accounts on LibraryThing so accounts were identified through snowball sampling. Through the LibraryThing Local application, libraries attached to a UK university were found to have accounts. Some libraries using LibraryThing were also identified through the literature review and one was found serendipitously through attendance by the researcher at a conference. LibraryThing provides a feature whereby a user can save profiles under the headings 'Friends' or 'Interesting Library' and also alerts a user to other libraries which have the same books in their collection as their own. Using the libraries identified through the literature and LibraryThing Local as starting points, libraries that they linked to on their profile, or that they were similar to, could be tracked to find other library profiles. Although using a snowball sampling technique means 
that the sample is not representative, it was the only viable approach in this situation (Bryman, 2012).

\subsection{Interviews}

Semi-structured interviews were conducted with four information professionals in total from two institutions chosen due to the convenience of their locations for the interviewer. The interviews were conducted to provide a better understanding of the use of LibraryThing by institutions and to inform the questionnaire design. At one institution, the person involved in the initial setting up of the library's LibraryThing account was not involved in the daily running of the account.

\subsection{Questionnaire}

The questionnaire was designed using Google Forms for ease of dissemination. Libraries were contacted using the email address provided on their LibraryThing profile, details provided on their institutional website, or by a private message sent on LibraryThing. A message was also posted on the 'Librarians who LibraryThing' group on LibraryThing and on the Jiscmail Lis-Link listerv.

\subsection{Data Analysis}

The interviews were analysed thematically using open coding (Strauss and Corbin, 1998). Answers were coded, either using the words of the interviewees if they were direct enough ("in vivo codes", Glaser and Strauss, 1967 in Strauss and Corbin, 1998, p.105) or by assigning codes. For example, when asked what the drawbacks of LibraryThing were, two participants claimed that a drawback was that LibraryThing is a third-party site. This term 'third-party site' was used as a code and incorporated directly into the questionnaire. This had the advantage of using terms used by librarians and which other librarians answering the questionnaire may then understand. The data obtained from the interviews was then combined with that gained through the survey to inform the conclusions of the study.

For the survey, the results were added to a spreadsheet, and coded to enable analysis (Bryman, 2012). Excel was used to create charts, and contingency tables were also created. Participants had the opportunity to provide detailed comments at the end of the questionnaire and these were analysed qualitatively, using open coding and thematic analysis.

\section{Results}

\subsection{Phase 1: Identification of LibraryThing features}

A list of possible uses of LibraryThing by libraries was identified from the literature and from personal knowledge (Table 1). This list was then used in the interviews and questionnaire. 
Table 1: Ways that LibraryThing can be used by libraries

\begin{tabular}{|l|l|}
\hline Promotional & User engagement \\
\hline $\begin{array}{l}\text { To highlight specific collections of books } \\
\text { e.g. those relating to an event or new stock. }\end{array}$ & $\begin{array}{l}\text { To create a book club selection list, using } \\
\text { LibraryThing recommendations or Common } \\
\text { Knowledge data }\end{array}$ \\
\hline $\begin{array}{l}\text { To highlight books on a blog or website } \\
\text { through a LibraryThing widget. }\end{array}$ & To help with Readers' Advisory \\
\hline $\begin{array}{l}\text { To create genre-specific book lists e.g. all } \\
\text { the crime novels held by a library }\end{array}$ & $\begin{array}{l}\text { To provide reviews of books held by the } \\
\text { library. }\end{array}$ \\
\hline $\begin{array}{l}\text { To promote library events through } \\
\text { LibraryThing Local }\end{array}$ & $\begin{array}{l}\text { Providing an online discussion group for } \\
\text { book clubs }\end{array}$ \\
\hline
\end{tabular}

In terms of user engagement the features are more compatible with public libraries, which may be because of the origins of LibraryThing as a way for individuals to catalogue their own personal book collections (LibraryThing, n.d.-a).

\subsection{Phase 2: Interviews}

Exploratory interviews were conducted with four people from two academic libraries identified as using Librarything, in order to understand their experiences.

The interviews began by discussing motivation for using social media and LibraryThing specifically. Factors which influenced the decision to begin using LibraryThing and which could be applied to social media generally, were that the tool is free or very cheap to use, the tool is user-friendly, the tool is part of a ready made network that the library could join and the tool incorporates Web 2.0 ideas. One interviewee had been aware of LibraryThing personally and knew that other libraries were using it in a way similar to how they wanted to use it, which influenced their decision to use it. The ability to link their LibraryThing account to other social media sites was also deemed important.

In terms of specific motivation for using LibraryThing one library used it to provide a web accessible catalogue for the library's users. Another reported that the library had moved to a new Library Management System that did not allow the creation of lists of new acquisitions. This was a feature that the library needed and therefore LibraryThing was used to fulfil this need.

The interviews then moved on to how each library used LibraryThing. The answers to this question mostly correlated with the reason why the library decided to use LibraryThing initially. However, at the institution where they used it to provide a web accessible catalogue they also used a LibraryThing widget to highlight books in the collection on a blog. At the other institution they were also considering using LibraryThing in additional ways, such as tagging the books so that students could search the catalogue or using it to highlight e-books. For both institutions, updating LibraryThing was not very time intensive and monitoring of patron usage was very low, although one institution did note when people bookmarked their account. Similarly, there had been little feedback from users. However, one participant mentioned that through committee interaction with undergraduate students she was aware that some students knew the tool existed. 
The final part of the interview investigated attitudes towards using LibraryThing. As the first participant worked in a library that did not use LibraryThing directly for promotional or user engagement purposes, the researcher asked whether they would be interested in using it in such a way, to which they answered yes. The other participants expressed interest in using LibraryThing to highlight specific collections of books, with participants from the second institution mentioning that they were looking to use it to create genre-specific book lists as well as using it to promote ebooks held by the library through placing a widget on their website.

In terms of whether LibraryThing added enough value to spend time on it, opinion was divided, with one participant expressing some reservations and two others mentioning that once the account had been set up it did not take much time to maintain it. This suggests that they felt that for how they wanted to use it, LibraryThing would not use up an undue amount of time. The benefits of using LibraryThing identified were ease of use, personalisation, accessibility, low cost and attractiveness. Drawbacks mentioned were that LibraryThing could not be used as a full Library Management System with report generating and circulation abilities, that LibraryThing is a third party site, outside of the library's control, that LibraryThing is not very good at facilitating social networking for libraries, and unless you paid for an account you could only add up to two hundred books. Finally, all participants agreed that LibraryThing was a useful tool for library services, although one participant expressed some reservations about how useful it would be for larger organisations. Another participant felt LibraryThing was particularly useful for public libraries whilst another mentioned that LibraryThing did have added value over the lists created by their old Library Management System as LibraryThing was a lot more attractive and allowed you to integrate the information into different websites, as well as allowing you to group different items how you wished.

\section{Summary}

Several factors were detailed as being important when considering using a new tool, including cost, ease of use, the presence of other libraries or a network of users, Web 2.0 features, and the ability to link the tool to other websites. LibraryThing was used differently by the two institutions, with one using it as an online catalogue, along with using a widget, and the other using it to highlight new acquisitions. Both institutions used it very infrequently and neither systematically monitored patron usage. Nor had either institution received much feedback regarding their use of LibraryThing. Three participants expressed interest in using LibraryThing to create book lists in particular. Advantages highlighted included ease of use, the ability to personalise your account, accessibility, attractiveness and low cost, whilst the drawbacks were that you could only have 200 books with a free account and the fact that LibraryThing is a third-party site. All interviewees except one expressed interest in using LibraryThing beyond their current use. All interviewees felt that LibraryThing was useful for library services.

\subsection{Phase 3: Questionnaire}

There were fifty-one complete responses. As requests for help were made via the Librarians who LibraryThing group and the Lis-Link listserv it is not possible to determine the response rate. Below are the results for each question. 
Which type of library do you work for?

Figure 2 details the types of library the respondents work for.

\section{Figure 2. Which type of library do you work for?}

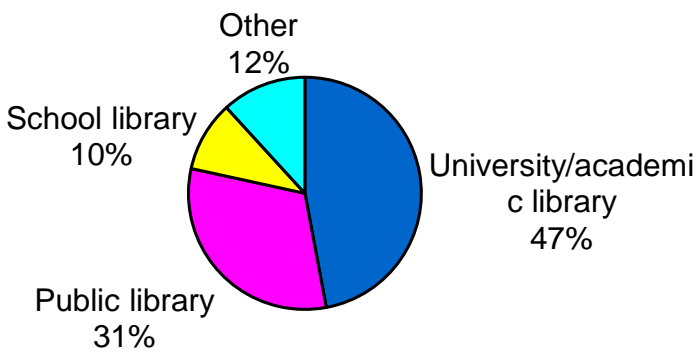

The majority of respondents worked in university/academic libraries, with public libraries second. The 'Other' responses included two health libraries (Questionnaire Respondent [hereafter QR] 2, QR43), a "community college" library (QR4), a "nonprofit organization" (QR11), a "career college library" (QR37), and a governmental library (QR40).

Why did your library decide to use LibraryThing?

Figure 3 shows the responses to this question.

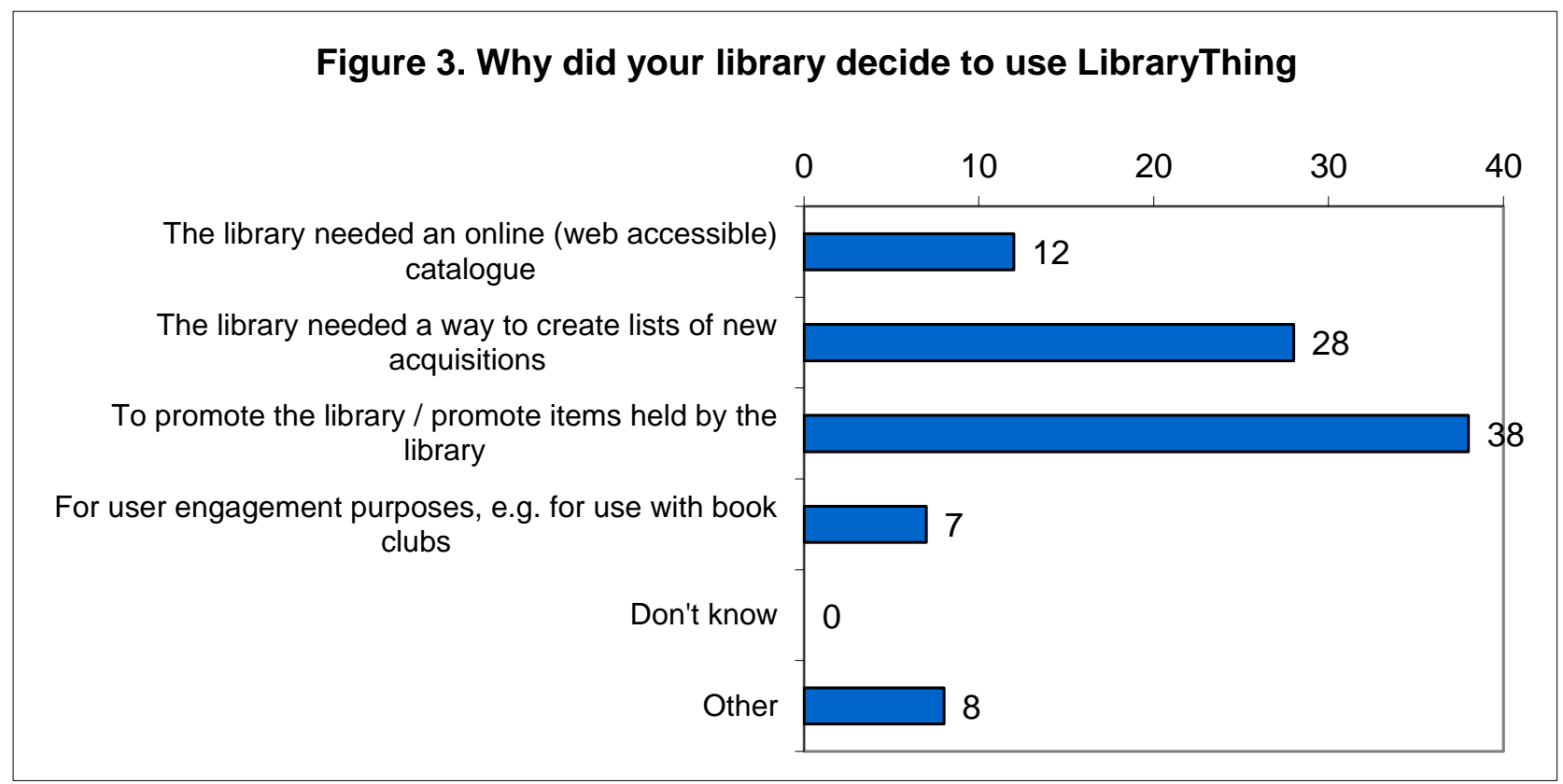

Other answers given under 'Other' include "for the tags" (QR24) and to "promote library events" (QR25), "To enhance access to a collection (graphic novels and manga) that is poorly served by a traditional library catalog [sic]" (QR28), and "Partly just experimentation - trying 
something different to see if it was useful" (QR43). QR50 explained that whilst they originally used LibraryThing for their online catalogue they now continue to use it alongside a traditional OPAC and QR44 stated that they originally used LibraryThing as a temporary measure as nothing was catalogued in the library. These results show that the primary reason libraries decide to use LibraryThing is to promote the library or to promote items held by the library, with respondents noting that they use it specifically to highlight new stock. The results were also broken down by library type (Table 2 ).

Table 2: The relationship between library type and the use of LibraryThing

\begin{tabular}{|l|l|l|l|l|}
\hline Reasons & $\begin{array}{l}\text { Library type } \\
\begin{array}{l}\text { University / } \\
\text { academic } \\
\text { library }\end{array}\end{array}$ & Public library & School library & Other \\
\hline No. / \% & No. / \% & No./\% & No. / \% \\
\hline Online catalogue & $2 / 8.3 \%{ }^{1}$ & $6 / 37.5 \%$ & $1 / 20 \%$ & $3 / 50 \%$ \\
\hline New acquisitions list & $18 / 75 \%$ & $8 / 50 \%$ & $1 / 20 \%$ & $1 / 16.7 \%$ \\
\hline $\begin{array}{l}\text { Promote the library / } \\
\text { items held by the } \\
\text { library }\end{array}$ & $18 / 75 \%$ & $12 / 75 \%$ & $4 / 80 \%$ & $4 / 66.7 \%$ \\
\hline User engagement & $3 / 12.5 \%$ & $2 / 12.5$ & $2 / 40 \%$ & $0 / 0 \%$ \\
\hline Other & $3 / 12.5 \%$ & $3 / 18.75 \%$ & $1 / 20 \%$ & $1 / 16.7 \%$ \\
\hline
\end{tabular}

Across all sectors, promotion of the library or library stock is the most popular reason why LibraryThing was used, with academic libraries using it for new acquisitions the most, although public libraries often used LibraryThing for this particular function. School libraries used LibraryThing for user engagement purposes, although the numbers are small.

How does your library use the LibraryThing website?

The most common way that respondents' libraries used LibraryThing was to highlight specific collections of books, such as new titles, with use of a LibraryThing widget on a blog or website coming second (Figure 4). Of the answers given as 'Other', six respondents mentioned specifically that they used LibraryThing to highlight new stock. QR36 also emphasised that they had used LibraryThing to promote new stock specifically because it provided an RSS feed feature. Another respondent, QR48, used it to highlight "staff picks". Overall 34 respondents used LibraryThing to promote specific collections of books, particularly new stock. Other uses included highlighting new DVD releases via a widget (QR41), including a "snapshot of [the] book" in reservation emails (QR13), "tagging books in the leisure collection" (QR24), and "to provide a supplement to our existing catalog [sic]" (QR28).

\footnotetext{
${ }^{1}$ Percentages are calculated to one decimal place. Also, participants could chose more than one answer and so percentages will amount to more than $100 \%$.
} 
Figure 4. How does your library use the LibraryThing website?

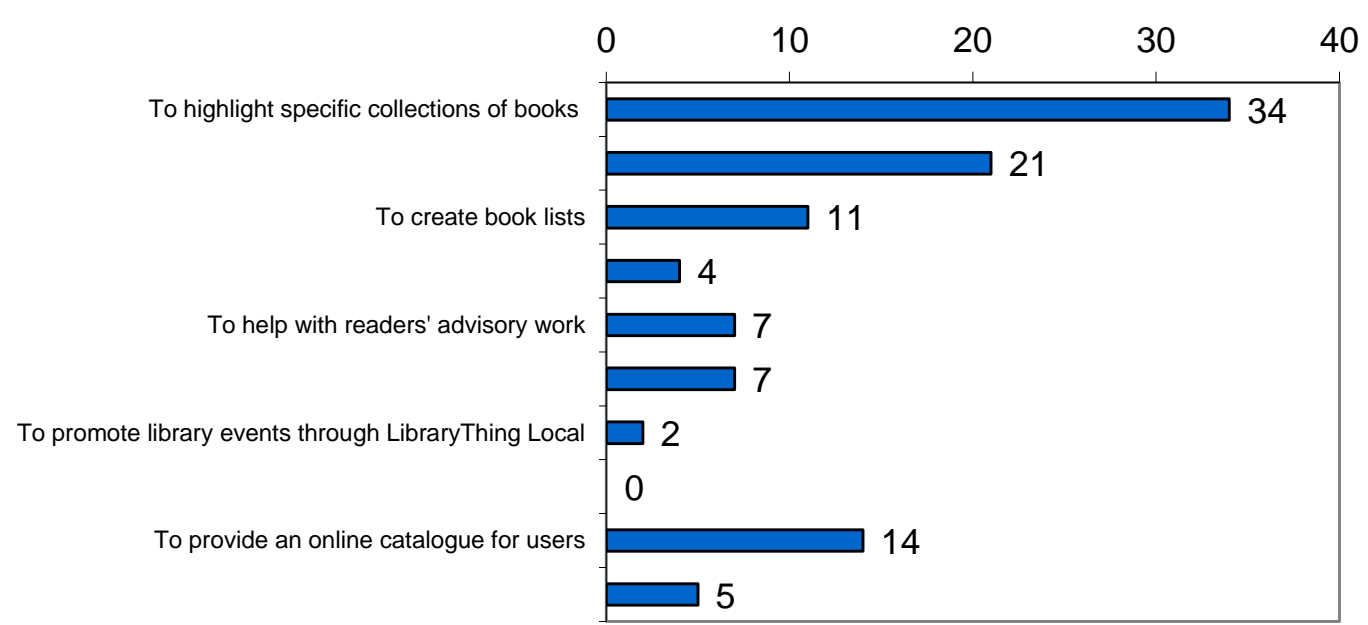

As with Question 3, the results were broken down by library type (Table 3).

Table 3: Contingency table. The relationship between library type and how a library uses LibraryThing

\begin{tabular}{|l|l|l|l|l|}
\hline Uses & Library type & & & \\
\hline & $\begin{array}{l}\text { University / } \\
\text { academic } \\
\text { library }\end{array}$ & Public library & School library & Other \\
\hline & No. / \% & No. / \% & No. / \% & No. / \% \\
\hline $\begin{array}{l}\text { To highlight specific } \\
\text { collections of books }\end{array}$ & $18 / 75 \%$ & $9 / 56.3 \%$ & $4 / 80 \%$ & $3 / 50 \%$ \\
\hline $\begin{array}{l}\text { To use a } \\
\text { LibraryThing widget }\end{array}$ & $12 / 50 \%$ & $5 / 31.3 \%$ & $3 / 60 \%$ & $1 / 16.7 \%$ \\
\hline To create book lists & $8 / 33.3 \%$ & $2 / 12.5 \%$ & $1 / 20 \%$ & $0 / 0 \%$ \\
\hline $\begin{array}{l}\text { To create a bookclub } \\
\text { selection list }\end{array}$ & $1 / 4.2 \%$ & $2 / 12.5 \%$ & $0 / 0 \%$ & $0 / 0 \%$ \\
\hline $\begin{array}{l}\text { To help with readers } \\
\text { advisory work }\end{array}$ & $0 / 0 \%$ & $4 / 25 \%$ & $2 / 40 \%$ & $1 / 16.7 \%$ \\
\hline To provide reviews & $1 / 4.2 \%$ & $2 / 12.5 \%$ & $2 / 40 \%$ & $2 / 33.3 \%$ \\
\hline $\begin{array}{l}\text { To use LibraryThing } \\
\text { Local }\end{array}$ & $0 / 0 \%$ & $2 / 12.5 \%$ & $0 / 0 \%$ & $0 / 0 \%$ \\
\hline $\begin{array}{l}\text { Online discussion } \\
\text { group for bookclubs }\end{array}$ & $0 / 0 \%$ & $0 / 0 \%$ & $0 / 0 \%$ & $0 / 0 \%$ \\
\hline Online catalogue & $4 / 16.7 \%$ & $5 / 31.3 \%$ & $2 / 40 \%$ & $3 / 50 \%$ \\
\hline Other & $2 / 8.3 \%$ & $2 / 12.5 \%$ & $1 / 20 \%$ & $0 / 0 \%$ \\
\hline
\end{tabular}

For university libraries, using LibraryThing to highlight specific collections of books was the most popular use. In comparison, the responses were more widely spread for public libraries, with only one answer (to provide an online discussion group for bookclubs) not selected. The 
highest percentage of widget use was by school libraries, with only $50 \%$ (12) of university libraries using it and only $31.3 \%$ (5) of public libraries, whilst respondents from public libraries were the only ones to use LibraryThing Local to promote events.

How often do you interact with or update your LibraryThing account?

Figure 5 shows that there is diversity in how often information professionals interact with their library's LibraryThing account, with 'Once a week' being the most common.

\section{Figure 5. How often do you interact with or update your LibraryThing account?}

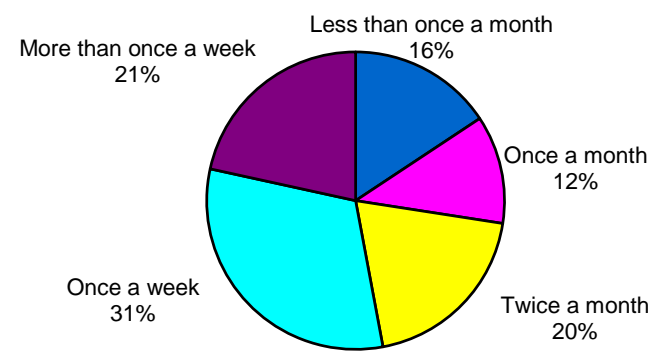

Do you monitor patron usage of your library's LibraryThing account?

By far the majority of respondents $(n=46)$ did not monitor patron usage of the library's LibraryThing account. Of the two respondents who did monitor patron usage, QR12 did not say how they monitored patron usage but claimed that they had "very little patron usage". QR19 said that they had embedded a LibraryThing widget into their library's LibGuide on which they could obtain statistics but that they did not check it regularly. The "don't know" option was selected by 3 respondents.

Have you had any feedback from users about your library's use of LibraryThing?

Only $31 \%$ (16) of respondents had received any feedback from users regarding their use of LibraryThing. Of these sixteen respondents, thirteen said they had had positive feedback, one had had negative feedback and two used the 'Other' option to expand on their answer. QR18 wrote "Students really like being able to find books similar to what they have just read. It provides very easy Readers' Advisory" whilst QR50 said that they had had "Positive feedback from librarian community and a little positive feedback from patrons." This means that overall 15 (94\%) of the respondents who had received feedback had received positive 
feedback with only $1(6 \%)$ receiving negative feedback. Unfortunately, no details were given regarding the negative feedback received.

This is a list of possible uses of LibraryThing for promotional/user engagement purposes. Do you think any of them would be useful for your library?

The most popular uses of LibraryThing for promotional and user engagement were 'To create book lists' and 'To highlight specific collections of books'(Figure 6). Respondents were asked to ignore current use. Seven respondents did not answer this question possibly because they did not think these options were useful for their library.

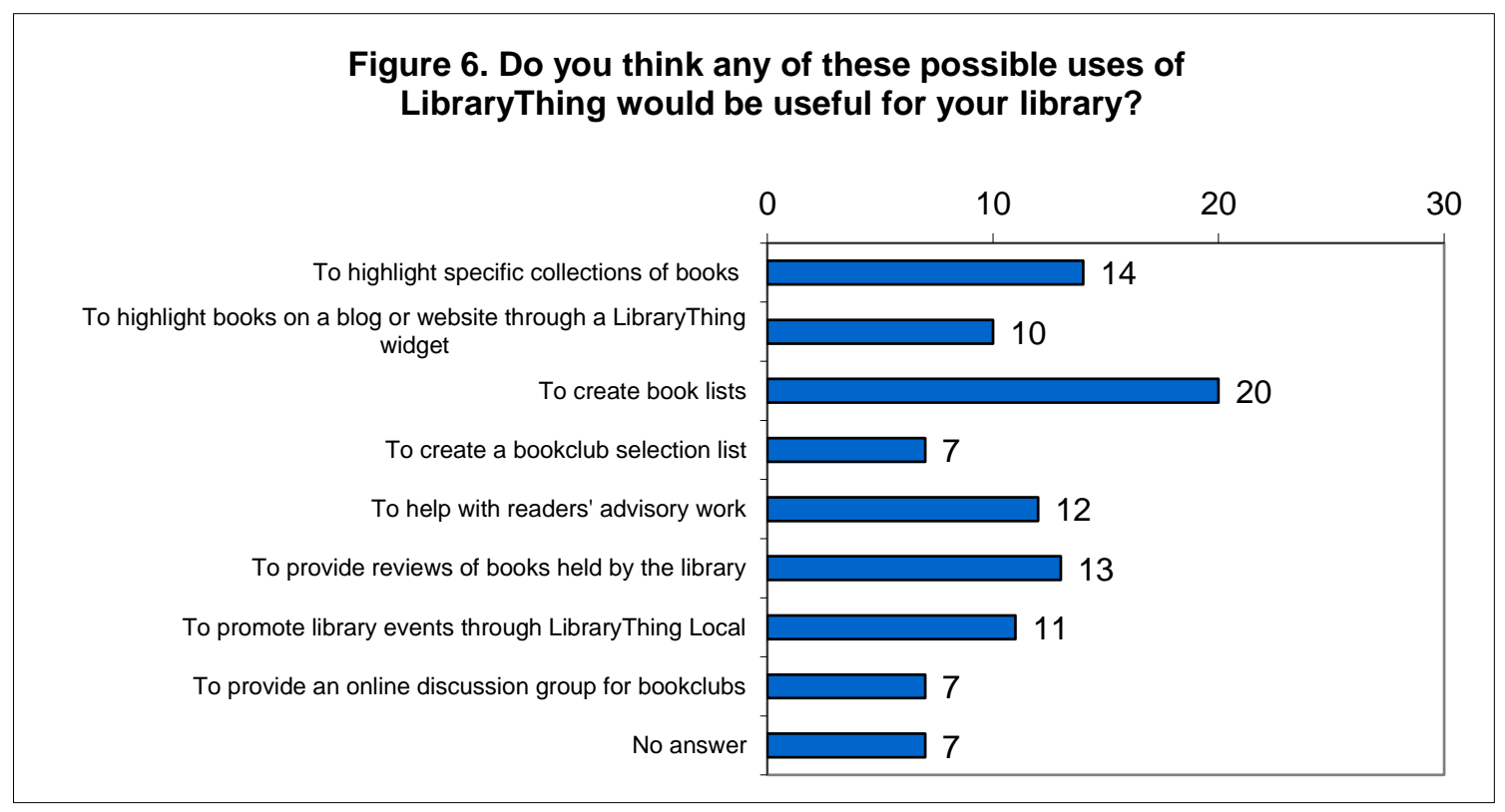


A contingency table has been created that shows the breakdown of results by library type.

Table 4: The relationship between library type and LibraryThing uses deemed useful by respondents

\begin{tabular}{|l|l|l|l|l|}
\hline Uses & $\begin{array}{l}\text { Library type } \\
\begin{array}{l}\text { University / } \\
\text { academic } \\
\text { library }\end{array}\end{array}$ & Public library & $\begin{array}{l}\text { School } \\
\text { library }\end{array}$ & Other \\
\hline No. / \% & No. / \% & No. / \% & No. / \% \\
\hline $\begin{array}{l}\text { To highlight specific } \\
\text { collections of books }\end{array}$ & $4 / 16.7 \%$ & $7 / 43.8 \%$ & $0 / 0 \%$ & $2 / 33.3 \%$ \\
\hline $\begin{array}{l}\text { To use a LibraryThing } \\
\text { widget }\end{array}$ & $4 / 16.7 \%$ & $3 / 18.8 \%$ & $0 / 0 \%$ & $3 / 50 \%$ \\
\hline To create book lists & $9 / 37.5 \%$ & $5 / 31.3 \%$ & $4 / 80 \%$ & $2 / 33.3 \%$ \\
\hline $\begin{array}{l}\text { To create a bookclub } \\
\text { selection list }\end{array}$ & $1 / 4.2 \%$ & $4 / 25 \%$ & $1 / 20 \%$ & $1 / 16.7 \%$ \\
\hline $\begin{array}{l}\text { To help with readers } \\
\text { advisory work }\end{array}$ & $6 / 25 \%$ & $6 / 37.5 \%$ & $0 / 0 \%$ & $0 / 0 \%$ \\
\hline To provide reviews & $3 / 12.5$ & $5 / 31.3 \%$ & $3 / 60 \%$ & $2 / 33.3 \%$ \\
\hline $\begin{array}{l}\text { To use LibraryThing } \\
\text { Local }\end{array}$ & $6 / 25 \%$ & $4 / 25 \%$ & $0 / 0 \%$ & $1 / 16.7 \%$ \\
\hline $\begin{array}{l}\text { Online discussion group } \\
\text { for bookclubs }\end{array}$ & $1 / 4.2 \%$ & $5 / 31.3 \%$ & $1 / 20 \%$ & $0 / 0 \%$ \\
\hline
\end{tabular}

This shows that when considering using LibraryThing beyond how they currently used it, respondents from university and school libraries felt that creating book lists would be the most useful, whilst for those from public libraries highlighting specific collections of books was most popular, followed by using LibraryThing for reader's advisory work.

Do you think that LibraryThing adds enough value to justify spending extra time on it?

The majority of respondents (35 or 69\%) felt that LibraryThing added enough value to justify spending extra time on it. However, $12(23 \%)$ respondents were undecided about the value it added to library services, and $4(8 \%)$ did not think it added enough value to justify spending extra time using it.

What do you think are the benefits of using LibraryThing?

The main advantages of LibraryThing identified by respondents were that it is free or very cheap and that it is easy to use, with its accessibility also scoring highly (Figure 7). Of the advantages given under 'Other', three respondents liked the tagging features of LibraryThing (QR 34; 51; 52), one liked "Functionality such as widgets and discussion forums" (QR41) and one respondent emphasised that they thought LibraryThing was "A great tool [sic]" (QR34). 


\section{Figure 7. What do you think are the benefits of using LibraryThing?}

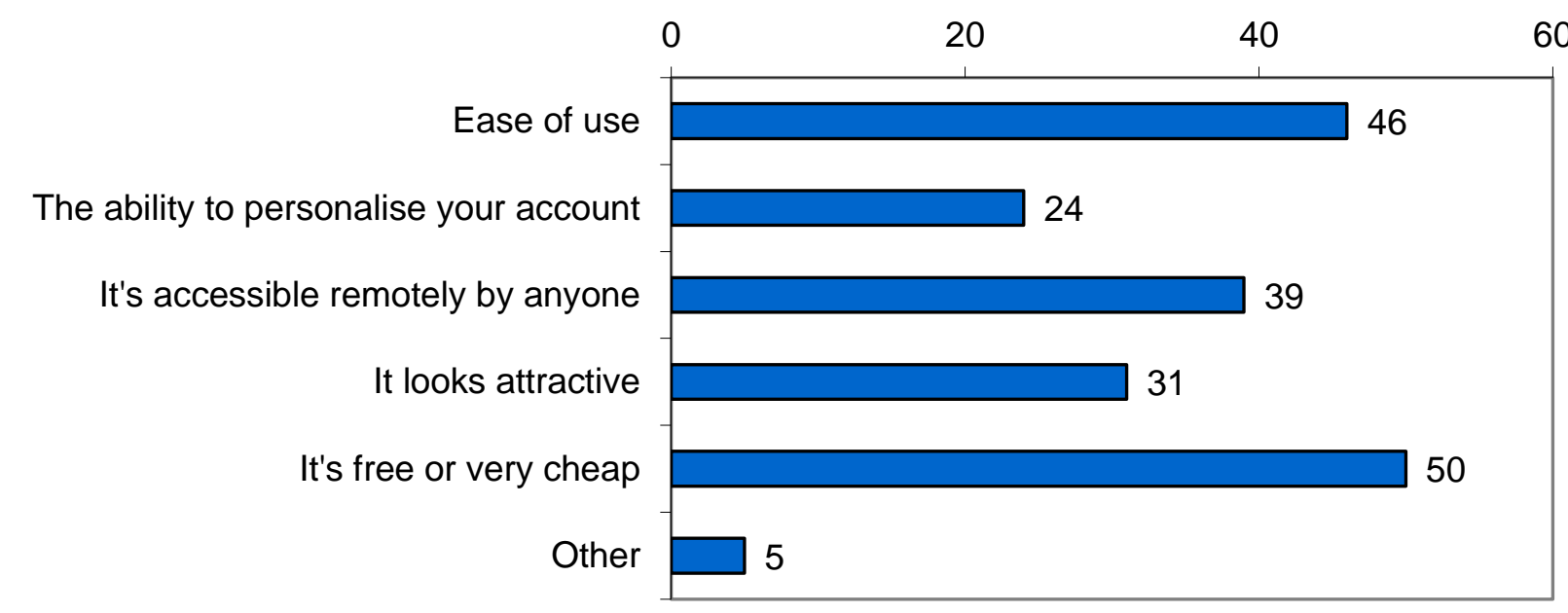

What do you think are the drawbacks of using LibraryThing?

The fact that LibraryThing is a third party site and the limit on how many books you can add before a fee is charged were both rated as the biggest drawbacks to using LibraryThing (Figure 8). The disadvantages mentioned under 'Other' include it being "a bit low-tech" (QR31), and issues around its lack of functionality e.g. "Doesn't do audiovisual such as DVDs" (QR44). Seven respondents did not answer this question.

Figure 8. What do you think are the drawbacks of using LibraryThing

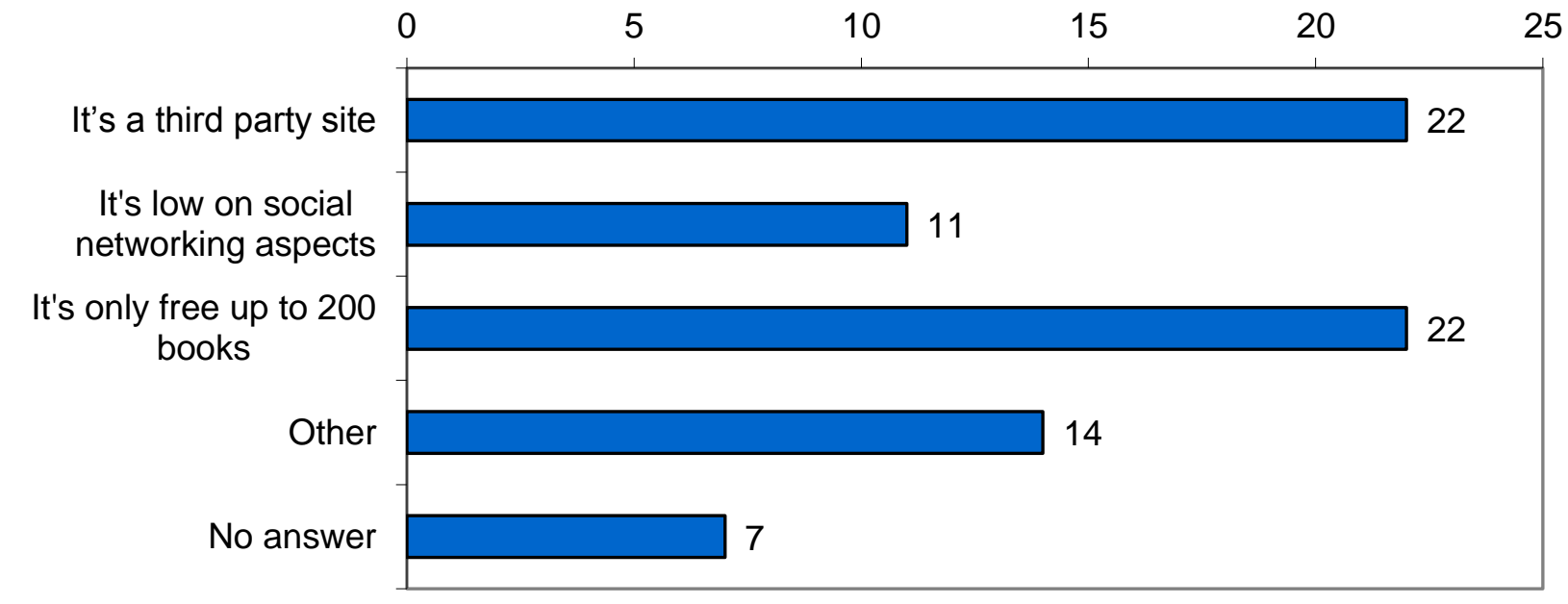

Do you as an information professional think LibraryThing is a useful tool for library services? 
Despite almost a third of respondents being uncertain whether LibraryThing added enough value to justify spending extra time on it or certain that it did not, 90\% (46) of respondents did think that LibraryThing was a useful tool for library services. Four respondents were undecided, and just one person did not think the tool was useful. It could be that whilst LibraryThing is seen as a valuable tool in itself by many information professionals, the time spent on it does not always result in enough benefits or feedback from users for information professional to feel it provides good return on investment.

\section{Summary}

In summary, we can see that almost half of the questionnaire respondents were from academic libraries, with public libraries being the second most represented. LibraryThing was mostly used for promotional activities, with a large amount of respondents using it specifically to promote new titles, whilst use of features relating to user engagement was low. How often respondents interacted with their LibraryThing account varied greatly, although the most common answer given was once a week. Most respondents did not monitor patron usage of their account and most had not received any feedback, although of those who had received feedback 94\% (15) had received positive feedback. In terms of uses beyond how respondents already used LibraryThing, creating book lists was the most popular use overall. The most popular benefits identified were the low cost of LibraryThing and its ease of use, whilst the most commonly chosen drawbacks were that it is a third-party site and that it is only free up to 200 books. That said, 69\% (35) of respondents felt that LibraryThing added enough value to justify spending extra time using it, with $90 \%$ (46) feeling that LibraryThing was a useful tool for library services.

\section{Discussion}

The literature review identified several ways in which libraries can use LibraryThing. Responses to the survey show that the most popular way in which LibraryThing is used is for promotion, with many respondents using it specifically for highlighting new stock. In terms of the uses of LibraryThing, highlighting specific collections of books (and in one case, DVDs) and using a LibraryThing widget are the most common. Others used LibraryThing to promote new teen books or to highlight popular fiction, book group titles or ebooks. This ability to create custom groupings of books was seen as a major advantage of LibraryThing, as confirmed in the literature (De Jager-Loftus, 2009; Harland, 2009; Rethlefsen, 2007). LibraryThing being used for promotion is shown by the choice of language used by several respondents: "We used to use LibraryThing to promote ebooks, faculty publications and new books," (QR52) "we use LibraryThing to advertise our new titles" (QR50), " a great marketing tool" (QR29).

Only two respondents mentioned promotion of events on LibraryThing Local, both of whom worked in public libraries. Not all survey respondents who used LibraryThing to promote stock used a LibraryThing widget on a blog or website. Thirty-seven respondents used LibraryThing to promote specific collections of books and/or for booklists but only 21 used a widget. One of the drawbacks of using LibraryThing identified in the literature review was that it would send users away from the library website (Feuille-blanche, 2011; Murphy, 2010). Use of a widget mitigates this drawback and provides a visually arresting way of displaying the items in the LibraryThing account so it is perhaps surprising that it was not always used, though one respondent mentioned that the widget was incompatible with their public library's blog and website. Hammond (2009), in her research into blog use in public 
libraries, found that many libraries in the UK did not allow their staff to access Web 2.0 technologies at work or that the IT departments did not help librarians to engage with this technology. The TechCrunch website also reported on a study into Web 2.0 use in government organisations and found that often such sites were blocked to staff (Butcher, 2008). It may be that a mixture of technical incompatibility and lack of institutional support for such endeavours mean that libraries cannot make use of the LibraryThing widget.

Another theme that arose from the data was enhanced access; one respondent had hoped that "LibraryThing might provide potential patrons with more exposure to our collection". This includes both the idea of increasing access to a collection and increasing awareness of a collection, a key goal of promotion, linking these two themes. On a basic level the use of LibraryThing as an online catalogue is a way of providing enhanced access to a library, since it allows people to see what is in the collection remotely. The fact that LibraryThing is accessible remotely was seen as an advantage of LibraryThing by many survey respondents. This idea of enhanced access goes beyond just making a collection available online. Several respondents mentioned the use of tags on LibraryThing and one respondent mentioned that LibraryThing allowed them to add as many tags as they wished, using users' terms, and the idea that tagging was helpful for students was also expressed. Several survey respondents also mentioned integrating LibraryThing with other tools, such as Twitter and Facebook or the library website and two discussed using the RSS facility provided by LibraryThing. These features increase the accessibility of not only the LibraryThing account but also the collection, since attention can be drawn to the books through different avenues and the use of tags could make it easier for patrons to identify useful items (Fichter, 2006; Lu, Park, and $\mathrm{Hu}$, 2010; and Rolla, 2009).

Use of LibraryThing for the user engagement features was low, with no respondents using it for online bookclubs. This reflects what was found in the literature review, where there was far more discussion of using LibraryThing in a promotional way than for user engagement, excepting using it for readers' advisory. One person said they found LibraryThing very useful for helping with reader's advisory. One respondent used LibraryThing for a reader's advisory task in such a way that they combined it with uses the researcher had originally categorised as promotional; they worked in a public library that ran an online reader's advisory service and all the books recommended through this service were catalogued on LibraryThing, since it allowed them to add comments and tags to the books. By making visible their recommendations they were promoting both their service and their books, showing that LibraryThing can be used successfully for a mixture of promotion and user engagement purposes. In a similar way, another respondent used LibraryThing to list books recommended by staff. This could be seen as a form of reader's advisory whilst at the same time promoting books held by the library.

In terms of the uses of LibraryThing that information professionals thought would be useful for their library beyond how they already used it, the idea of creating book lists, such as all the books on a certain subject, was the most popular response. Although use of LibraryThing for user engagement purposes was low, many librarians did see the use of LibraryThing for tasks such as reader's advisory and to provide reviews. These uses were more popular with public and school libraries, rather than in academic libraries, although $25 \%$ (6) of respondents from academic libraries thought that LibraryThing would be helpful for reader's advisory. This suggests that information professionals can see a use for LibraryThing in helping with user engagement, even though promotional uses were the most popular. 
All of the advantages of LibraryThing rated most highly (it's free or very cheap, ease of use, and it's remotely accessible) can be seen as relating to the theme of accessibility. The low cost of LibraryThing means it is very financially accessible for libraries and so the fact that one of the most chosen drawbacks to using LibraryThing was the book limit for free accounts is related to this. Ease of use was the second most popular advantage identified in the survey and was mentioned often in the comments and in all three interviews.

However, drawbacks other than the limit on books for free accounts were identified. The fact that LibraryThing is a third party site was chosen as a drawback by 22 respondents and was also discussed in the interviews and in the literature. Some questionnaire respondents echoed this desire to have something that is made specifically for libraries or is part of the Library Management System: "Wish it could be somehow integrated into our regular catalogue" (QR28), "It would be nice to have the option of a more "professional" look \& feel" (QR43), "I would like 2 levels of interaction; 1 for librarians... and 1 for users" (QR46). Additionally, some respondents remarked on the lack of interactivity with other libraries, claiming that Goodreads was used by more members of the public. This lack of interactivity may be why not many libraries currently use LibraryThing for user engagement purposes.

Another drawback identified in the survey is that of time spent. Although only two respondents mentioned the extra time needed to put books onto LibraryThing others did discuss it in their comments at the end of the questionnaire, using terms such as "the tiresomeness of transferring data" (QR2), "overstretching our staff to accommodate adding to LT [sic]" (QR12), "double the work" (QR29), and "there just aren't enough hours in the day to put into LT [sic]" (QR9). Conversely, one person said that their library continued to use LibraryThing to promote new stock (they originally used it as their online catalogue) because it was easy to maintain and provided a constantly changing widget on their website without any added work on their part. The idea that LibraryThing does not take too much time to maintain was also echoed by the interviewees. Thus, whether LibraryThing is seen as being time consuming may depend on how it is used and the time constraints of individual libraries.

Although the majority of respondents $(68 \%, 35)$ thought LibraryThing did add enough value to justify spending extra time on it, 32\% (16) either did not think it was worth spending time with LibraryThing or were undecided. On the other hand, 90\% (46) of respondents thought that LibraryThing was a useful tool for library services and the majority of respondents chose at least one option when asked if any of the identified uses of LibraryThing would be helpful for their library. It could be that whilst LibraryThing is seen as a valuable tool in itself by many librarians, the time spent on it does not always result in enough benefits or feedback from users for information professionals to feel it provides good return on investment. Indeed, one respondent claimed that the lack of "positive return on our investment of time and energy" (QR12) meant that they were considering discontinuing their use of LibraryThing, whilst another (QR52) said that lack of feedback was why they now only used LibraryThing Local to promote events. This shows how important feedback is when evaluating the success of a tool. Although 15 of the 16 who had received feedback received positive feedback, the majority of respondents did not receive any feedback $(67 \%, 34)$ and even less monitored use in any way $(90 \%, 46)$. This echoes what was found in the interviews, where feedback was minimal and monitoring of the account was not systematic or was nonexistent.

As discussed in the literature review there are ways in which libraries could monitor patron use of LibraryThing. Fichter and Wisniewski (2008) suggest, for example, monitoring 
Delicious, to see whether people are bookmarking your website, or using services such as Google Analytics or Clicky Web Analytics to monitor how many people sign up for an RSS feed and how people reach a particular web page. Although Fichter and Wisniewski (2008) advise investigating beyond web page views, this is an easy metric that could be used by libraries to judge whether their LibraryThing profile is being viewed and such data will be generated by a service such as Google Analytics (Google, n.d.). Moreover, one respondent said that they were able to collect statistical data from their LibraryThing widget so this is another way of identifying user engagement with a library's LibraryThing account. Librarians could also actively solicit feedback from patrons, for example through face-to-face interviews or surveys of their own (Fichter and Wisniewski, 2008).

The final research objective was to evaluate the overall value of LibraryThing for libraries. This study finds that LibraryThing is most valuable for libraries as a promotional tool, using it to highlight specific collections of books that would be of interest for users, such as new stock or books on a specific topic. However, it can be used successfully for readers' advisory work, especially if it is used to highlight staff recommendations, since this harnesses the promotional value of LibraryThing. It has less use for user engagement, possibly because the number of library patrons using LibraryThing is low.

\section{Conclusion}

The aim of this research was to evaluate the value of LibraryThing for libraries when using it for promotional and user engagement purposes.

The literature review and the large amount of libraries found that use LibraryThing show that librarians have identified LibraryThing as a potentially useful tool. In terms of promotion and user engagement, several uses have been identified. The most popular way of using LibraryThing was to promote stock by highlighting specific collections of books such as new stock or wider collections, such as all the ebooks held by a library. Conversely, use of LibraryThing Local to promote events was low, as was use of LibraryThing for user engagement purposes. Of the features identified as being for user engagement, the most popular were to help with reader's advisory work and to provide reviews. Indeed, one respondent used LibraryThing to highlight the books recommended through their reader's advisory service, showing that promotion and user engagement are not mutually exclusive. The majority of questionnaire respondents and all the interviewees felt that LibraryThing was a useful tool for libraries, although opinion was more divided on whether LibraryThing added enough value to justify spending extra time on it, with only $68 \%$ (35) of questionnaire respondents thinking it did add enough value. The most popular benefits of using LibraryThing identified were its cost effectiveness, the fact that it is easy to use, and that it is remotely accessible, whilst the main drawbacks were that it is only free up to 200 books and that it is a third party site.

This study concludes that LibraryThing is a valuable promotional tool for libraries when used to promote particular collections of books and that it has less value as a tool for user engagement. It is thus recommended that libraries use it to promote collections of books to their users. It is also recommended that libraries use the LibraryThing widget, as this will integrate LibraryThing into their own website or blog and thus incorporate it to some extent into the library brand, as well as easily promoting their use of the website. However, librarians may want to check whether the widget is compatible with their website or blog 
before beginning to use LibraryThing, since if it is not then their ability to promote their use of LibraryThing may be diminished. Although there are some drawbacks to be aware of, such as the fact that it is a third-party site or that it is only free for 200 books, the majority of respondents in this study did feel that LibraryThing was a useful tool for library services. Nevertheless, it would be worthwhile for any libraries considering using LibraryThing to identify not only how best to use LibraryThing for their users but also how they are going to monitor use and solicit feedback so that they can identify whether it is a truly useful service for their own library. Also, a limitation of this investigation was that it considered use of the LibraryThing website only. Libraries interested in using LibraryThing may want to investigate use of the LibraryThing APIs, which allows users to use some LibraryThing data in custom applications (LibraryThing, n.d.-f), or the LibraryThing for Libraries and Library Anywhere developments.

[1] This article is based on a dissertation written as part of the requirements for the degree of Master of Arts in Librarianship at the University of Sheffield 2012.

[2] Video equivalent of podcast (Oxford Dictionaries, 2012a;b).

[3] A widget "is a small program that you can easily put on your website, blog, or personalized start page" (Nations, 2012, paragraph 1). On LibraryThing, widgets can include a changing view of book covers in your library, tags, or a search box (LibraryThing, n.d.-e)

[4] See, for example, http://www.librarything.com/work/8101931/commonknowledge

\section{Appendix A}

Below is a copy of the questionnaire used for the research.

\section{A questionnaire on library use of the LibraryThing website}

Please answer the questions honestly and to the best of your ability. All answers are anonymous. By checking the box below you are giving your consent to participate in this study and for your data to be recorded and used in the report.

$\square$ I agree to take part in this study and for the data that I provide to be recorded and used.

1. Which type of library do you work for?

University / academic library

Public library

School library

Other

2. Thinking generally, what factors influence your decision to start using a new social media tool? Choose any options that apply. 'If 'Other' please expand on your answer.

The tool is free or very cheap

The tool is easy to use

The tool provides a ready to use network the library can join

The tool incorporates Web 2.0 features e.g. tagging

Other libraries are using the tool

It can be linked with other social media tools

3. Why did your library decide to use LibraryThing?

Choose any options that apply. If 'Other' please expand on your answer.

The library needed an online (web accessible) catalogue

The library needed a way to create lists of new acquisitions 
To promote the library / promote items held by the library

For user engagement purposes e.g. for use with book clubs

Don't know

Other

4. How does your library use the LibraryThing website?

Choose any options that apply. If 'Other' please expand on your answer.

To highlight specific collections of books e.g. those relating to an event or new stock

To highlight books on a blog or website through a LibraryThing widget

To create book lists e.g. genre-specific book lists for users such as all the crime novels held by the library

To create a book club selection list, using LibraryThing recommendations or Common

Knowledge data

To help with readers' advisory work

To provide reviews of books held by the library

To promote library events through LibraryThing Local

To provide an online discussion group for book clubs

To provide an online catalogue for users

Other

5. How often do you interact with or update your LibraryThing account?

Choose an approximate length of time if the exact amount is not known.

Less than once a month

Once a month

Twice a month

Once a week

More than once a week

6. Do you monitor patron usage of your library's LibraryThing account?

Yes

No

Don't know

6b. If you answered 'Yes' to the above question, how do you do this?

7. Have you had any feedback from users about your library's use of LibraryThing?

Yes

No

Don't know

7b. If you answered 'Yes' to the above question, what kind of feedback have you received?

if you would like you can expand on your answer using the 'Other' option.

Positive

Negative

Other

8. This is a list of possible uses of LibraryThing for promotional/user engagement purposes. Do you think any of them would be useful for your library? Ignore any that your library already uses.

To highlight specific collections of books e.g. those relating to an event or new stock 
To highlight books on a blog or website through a LibraryThing widget

To create book lists e.g. genre-specific book lists for users such as all the crime novels held by the library

To create a book club selection list, using LibraryThing recommendations or Common Knowledge data

To help with readers' advisory work

To provide reviews of books held by the library

To promote library events through LibraryThing Local

To provide an online discussion group for book clubs

9. Do you think that LibraryThing adds enough value to justify spending extra time on it?

Yes I do think that LibraryThing adds enough value to justify spending extra time on it No I don't think that LibraryThing adds enough value to justify spending extra time on it Undecided

10. What do you think are the benefits of using LibraryThing?

Choose any options that apply. If 'Other' please expand on your answer.

Ease of use

The ability to personalise your account e.g. choice of book covers

It's accessible remotely by anyone

It looks attractive

It's free or very cheap

Other

11. What do you think are the drawbacks of using LibraryThing?

Choose any options that apply. If 'Other' please expand on your answer.

It's a third party site i.e. you don't know if it will go down or be hacked

It's low on social networking aspects

It's low on social networking aspects

Other

12. Do you as an information professional think LibraryThing is a useful tool for library services?

Yes it is a useful tool

No it isn't a useful tool

Undecided

If there is anything you would like to add please do so here.

\section{References}

23 Things Oxford. (2010, July 26), "23 Things Summer Camp: LibraryThing”, 23 Things Oxford, available at http://23thingsoxford.blogspot.co.uk/2010/07/23-things-summer-camplibrarything.html.(Accessed 23 July 2012)

Abdulhadi, M., Clough, P., \& Sen, B. (2012), "Collaborative social tagging and information literacy" [Poster], presented at LILAC 2012, 11-13th April, Glasgow.

Anttiroiko, A.V., \& Savolainen, R. (2011), "Towards Library 2.0: The adoption of Web 2.0 Technologies in public libraries", Libri, Vol 61, No.2, pp.87-99. 
Bates, J., \& Rowley, J. (2011), "Social reproduction and exclusion in subject indexing: a comparison of public library OPACS and LibraryThing folksonomy", Journal of Documentation, Vol 67, No. 3, pp.431-448.

Birkwood, K. (2011, July 16), "Thing 14: 'I understand not what you mean by this", Girl in the Moon, available at http://maedchenimmond.blogspot.co.uk/2010/07/i-understand-notwhat-you-mean-by-this.html(Accessed 25 July 2012)

Blumenstein, L. (2007), “A public library tries LibraryThing”, Library Journal, Vol. 132, No.11, p.16.

Bryman, A. C. (2012), Social research methods (4th.ed.), Oxford University Press: Oxford.

Buigues-Garcia, M., \& Gimenez-Chornet, V. (2012), "Impact of Web 2.0 on national libraries", International Journal of Information Management, Vol. 32, No.1, pp.3-10.

Butcher, M. (2008, August 5) "Government workers want social tools - but the IT dept doesn't get it", TechCrunch, available at http://techcrunch.com/2008/08/05/governmentpeople-want-social-tools-but-the-it-dept-doesnt-get-it/ (Accessed 10 August 2012)

Chua, A. Y. K., \& Goh, D. H. (2010), "A study of Web 2.0 applications in library websites", Library and Information Science Research, Vol. 32, No.3, pp.203-211.

Cragg, E. (2010,. "Use of social media in the member libraries of the Business Librarians Association", SCONUL Focus, Vol.49, No.1, pp.12-14.

De Jager-Loftus, D. (2009), "Value-added technologies for liaison and outreach", Journal of Electronic Resources in Medical Libraries, Vol. 6, No.4, pp.307-315.

De La Cruz, J. (2011, December 8), "Digital Makeover: Updating a Study Abroad Library", Hack Library School, available at http://hacklibschool.wordpress.com/2011/12/08/fsuflorence/ (Accessed 20 July 2012)

Eesiem. (2007, September 30), “Assignment: Using LibraryThing in Your School Library (Web 2.0 Tool Review)", Learning the Library Way, available at http://eesiem.wordpress.com/2007/09/30/assignment-using-librarything-in-your-schoollibrary/(Accessed 20 July 2012)

Feuille-blanche. (2011, August 11), "Thing 13: LibraryThing (with a diversionary comment on Narcissism, if you'll forgive my self-indulgence...)", Alliteration Station, available at http://feuille-blanche.blogspot.co.uk/2011/08/thing-13-librarything-with-diversionary.html (Accessed 23 July 2012)

Fichter, D. (2006), "Intranet applications for tagging and folksonomies", Online, Vol.30, No.3, pp.43-45.

Fichter, D., \& Wisniewski, J. (2008), "Social media metrics: Making the case for making the effort”, Online, Nov/Dec, pp. 54-57. 
Goodreads Inc. (2012a), "Tortall and Other Lands: A Collection of Tales by Tamora Pierce Reviews, Discussion, Bookclubs, Lists", avialable at http://www.goodreads.com/book/show/8396340-tortall-and-other-lands?origin=recs_landing (Acccessed 20 June 2012)

Goodreads Inc. (2012b), "Goodreads | Recommended for You”, available at http://www.goodreads.com/recommendations (Accessed 20 June 2012)

Google (n.d.), "Content analytics", available at http://www.google.com/analytics/features/content.html (Accessed 21 August 2012)

Hammond, S. (2009), How are public libraries engaging with Library 2.0? (Masters), University of Sheffield, Sheffield.

Han, Z., \& Liu, Y. Q. (2010), "Web 2.0 applications in top Chinese university libraries", Library Hi Tech, Vol.28, No.1, pp. 41-62.

Harinarayana, N., \& Raju, N. V. (2010), "Web 2.0 features in university library web sites", The Electronic Library, Vol.28, No.1, pp.69-88.

Harland, P. (2009), "Library 2.0 in Plymouth, New Hampshire: How one library uses Web 2.0 tools to enhance services to students and staff", Library Media Connection, Vol.27, No.5, pp.57-58.

Harris, C. (2006), "School Library 2.0”, School Library Journal, (5). available at http://www.schoollibraryjournal.com/article/CA6330755.html (Accessed 20 July 2012)

Hastings, R. (2009), “The LibraryThing API and libraries", Engard, N.C., Library mashups: exploring new ways to deliver library data, Facet Publishing: London, pp. 243-252.

Ishizuka, K. (2006), “A book lover's MySpace”, School Library Journal, Vol.52, No.10, pp.24-5.

Jeffries, S. (2008), "Social cataloguing tools: a comparison and application for librarians2, Library Hi Tech News, Vol.25, No.10, pp.1-4.

Kim, Y., \& Abbas, J. (2010), “Adoption of Library 2.0 functionalities by academic libraries and users: a knowledge management perspective", Journal of Academic Librarianship, Vol.36, No.3, pp.211-218.

Koltay, T. (2010), "The Web 2.0 contradiction: Commercial and library use", Library Philosophy and Practice, December, available at http://www.webpages.uidaho.edu/ mbolin/koltay.htm (Accessed 15 June 2012)

Koppenhaver, C. (2011), "Goodreads business cards connect with readers", Voice of Youth Advocates, Vol.34, No.4, p.331.

Kozel-Gains, M., \& Stoddart, R. (2009), "Experiments and experiences in liaison activities: Lessons from new librarians in integrating technology, face-to-face, and follow up", Collection Management, Vol.34, No.2, pp.130-142. 
Lawson, K. (2009), "Mining social tagging data for enhanced subject access for readers and researchers", The Journal of Academic Librarianship, Vol.35, No.6, pp.574-582.

LibraryBug. (2008, March 17), "Web 2.0 Tool Review: LibraryThing”, Library Bug, accessible from http://librarybug.wordpress.com/2008/03/17/web-20-tool-reviewlibrarything/(Accessed 20 July 2012)

LibraryThing. (2006, September 16), "How libraries are using LibraryThing" The LibraryThing Blog, available at http://www.librarything.com/blogs/librarything/2006/09/how-libraries-are-usinglibrarything/(Accessed 26 July 2012)

LibraryThing. (n.d.-a), “About”, available at http://www.librarything.com/about (Accessed from 7 April 2012)

LibraryThing. (n.d.-b), "Short introduction", available at http://www.librarything.com/quickstart.php (Accessed 21 August 2012)

LibraryThing. (n.d.-c), "LibraryThing for Libraries", available at http://www.librarything.com/forlibraries (Accessed 7 April 2012)

LibraryThing (n.d.-d), "How libraries can use LibraryThing", available at http://www.librarything.com/about/libraries (Accessed 7 April 2012)

LibraryThing (n.d.-e), "Widgets and extensions", available at http://www.librarything.com/more/widgets (Accessed 7 April 2012)

LibraryThing (n.d.-f), "LibraryThing APIs", available at http://www.librarything.com/services/ (Accessed 20 April 2013)

Lu, C., Park, J., \& Hu, X. (2010), "User tags versus expert-assigned subject terms: a comparison of LibraryThing tags and Library of Congress Subject Headings", Journal of Information Science, Vol.36, No.6, pp.763-779.

Mahmood, K., \& Richardson Jr., J. V. (2011), “Adoption of Web 2.0 in US academic libraries: a survey of ARL library websites", Program: electronic library and information systems, Vol.45, No.4, pp.365-375.

Manchester Lit List. (2010, June 27), "Islington Mill Art Reference Library on LibraryThing", Manchester Lit List, available at http://manchesterlitlist.blogspot.co.uk/2010/06/islington-mill-art-reference-library-on.html (Accessed 23 July 2012)

McMorland, L., Tolnay, M., \& Vick, R. (2010), "Public libraries giving high school students a break", Australasian Public Libraries and Information Services, Vol.23, No.2, pp.67-73.

Mendes, L. H., Quinonez-Skinner, J., \& Skaggs, D. (2009), "Subjecting the catalog to tagging”, Library Hi Tech, Vol.27, No.1, pp.30-41. 
Millar, L.A. (2010). Archives: Principles and practices. Facet Publishing: London

Morse, J. M. (2003), "Principles of mixed methods and multimethod research design", Tashakkori, A \& Teddlie, C., Handbook of mixed methods in social and behavioral research, Sage:Thousand Oaks, CA; London, pp.189-208.

Mukcomlibrary. (2011, August 15), "Worth a Look: LibraryThing", Mukwonago Community Library Blog, available at http://mukcomlibrary.blogspot.co.uk/2011/08/worth-looklibrarything.html (Accessed 23 July 2012)

Murphy, H. (2010, July 26), "Thing 14: LibraryThing for libraries, with apologies to Simon le Bon", Library Wanderer, available at http://librarywanderer.blogspot.co.uk/2010/07/thing14-librarything-for-libraries.html (Accessed 23 July 2012)

Nair, M. (2011), "Understanding and measuring the value of social media”, Journal of Corporate Accounting, March/April, pp.45-51.

Nations, D. (2012), "What are web widgets? How can I use a web widget?", available at http://webtrends.about.com/od/widgets/a/what_is_widget.htm (Accessed 21 August 2012)

Nesta, F., \& Mi, J. (2011), "Library 2.0 or Library III: returning to leadership", Library Management, Vol.32, No.1/2, pp.85-97.

Nuffield College Library. (2010, February 17), "How to keep up to date with our new books", Nuffield College Library's Blog, available at http://nuffieldcollegelibrary.wordpress.com/2010/02/17/how-to-keep-up-to-date-with-ournew-books/ (Accessed 20 July 2012)

O’Leary, N. (2012), "Reading dead? No way! See Goodreads”, Information Today, Vol.29, No.1, pp.22-23.

O’Neill, J. (2009, February), “Thing 13: Library Thing”, 23 Things @ NEFLIN, available at http://neflins23things.blogspot.co.uk/2009/02/thing-13-library-thing.html (Accessed 23 July 2012)

O'Reilly, T. (2005), "What is Web 2.0?", available at http://oreilly.com/pub/a/web2/archive/what-is-web-20.html?page=1 (Accessed 09 April 2012)

Oxford Dictionaries (2012a), "Vodcast", available at http://oxforddictionaries.com/definition/english/vodcast?q=vodcast (Accessed 21 August 2012)

Oxford Dictionaries (2012b), "Videocast", available at http://oxforddictionaries.com/definition/english/videocast?q=videocast (Accessed 21 August 2012)

Pacheco, J., Kuhn, I., \& Grant, V. (2010), "Librarians use of Web 2.0 in UK medical schools: outcomes of a national survey", New Review of Academic Librarianship, Vol.16, No.1, pp.7586. 
Ram, S., Anbu K, J. P., \& Kataria, S. (2011), "Responding to user's expectation in the library: innovative Web 2.0 applications at JUIT Library: A case study [sic]", Program: electronic library and information systems, Vol.45, No.4, pp.452-469.

Rapp, D. (2011), “Crowdsourcing RA”, Library Journal, Vol.136, No.10, pp.56-7.

Rethlefsen, M. L. (2007), “Tags help make libraries Del.icio.us”, Library Journal, Vol.132, No.15, pp.26-28.

Rolla, P. (2009), "User tags versus subject headings: can user-supplied data improve subject access to library collections?", Library Resources and Technical Services, Vol.53, No.3, pp.174-184.

Romero, N. L. (2011), "ROI. Measuring the social media return on investment in a library", The Bottom Line: Managing Library Finances, Vol.24, No.2, pp.145-151.

Secret Library Island. (2010, July 23), "The thing about LibraryThing (Things 14 \& 15)", Secret Library Island, available at http://secretlibraryisland.wordpress.com/2010/07/23/thething-about-librarything-things-14-15/ (Accessed 20 July 2012)

Seshat scribe. (2010, August 17), "LibraryThing", Seshat Scribe, available at http://seshatscribe.blogspot.co.uk/2010/08/librarything.html (Accessed 23 July 2012)

Sheehan, K. (2007), "LibraryThing for Libraries” NetConnect, supplement to Library Journal, Summer, p.3.

Shelfari. (2012a), “The Hobbit: or There and Back Again by J. R. R. Tolkien”, available at http://www.shelfari.com/books/10466/The-Hobbit (Accessed 20 June 2012)

Shelfari. (2012b), "Exploring Shelfari Community", available at http://www.shelfari.com/members (Accessed 20 June 2012)

Solis, B. (2011). Engage!: The complete guide for brands and businesses to build, cultivate, and measure success in the new web. Wiley: Hoboken, N.J.

Starr, J (2008), "Social networks: another avenue to new books and friends", Searcher, Vol.16 No.6, pp.42-3, 45, 47-8.

Steiner, S. (2008), “Goodreads, Library Thing, and Shelfari”, Cooke, N. (Ed.), "Social networking in libraries: New tricks of the trade, part II" (pp. 357-8), Public Services Quarterly, Vol.4, No.4, pp.353-365.

Strauss, A. \& Corbin, J. (1998), Basics of qualitative research: Techniques and procedures for developing Grounded Theory ( $2^{\text {nd }}$ ed.), Sage: Thousand Oaks, CA; London.

Tay, A. (2010, January 21), "Location based services/pages your library should claim or monitor", Musings about librarianship, available at http://musingsaboutlibrarianship.blogspot.co.uk/2010/01/location-based-servicespagesyour.html (Accessed 23 July 2012) 
Teddlie, C., \& Tashakkori, A. (2009), Foundations of mixed methods research: integrating quantitative and qualitative approaches in the social and behavioral sciences. Sage: Los Angeles; London.

Tripathi, M., \& Kumar, S. (2010), "Use of Web 2.0 tools in academic libraries: a reconnaissance of the international landscape", International Information and Library Review, Vol.42, No.3, pp.195-207.

Vere Harmsworth Library. (2007, December 5), "VHL on LibraryThing", Vere Harmsworth Library, available at http://vereharmsworthlibrary.blogspot.co.uk/2007/12/vhl-onlibrarything.html (Accessed 23 July 2012)

Wakeling, S., Clough, P., \& Sen, B. (2012) "“Readers who borrowed this also borrowed...': recommender systems in UK libraries", Library Hi Tech, Vol.30, No.1, pp.134-150.

Webb, P. L., \& Nero, M. D. (2009), "OPACS in the clouds", Computers in Libraries, Vol.29, No.9, pp.18-22.

Westcott, J., Chappell, A., \& Lebel, C. (2009), "LibraryThing for Libraries at Claremont", Library Hi Tech, Vol.27, No.1, pp.78-81.

Wright, D., \& Bass, A. (2010), "No reader is an island: new strategies for readers' advisory", Alki, Vol.26, No.3, pp.9-10.

Wyatt, N. (2007), “2.0 for readers”, Library Journal, Vol.132, No.18, pp.30-33.

$\mathrm{Xu}, \mathrm{C}$., Ouyang, F., \& Chu, H. (2009), "The academic library meets Web 2.0: applications and implications", Journal of Academic Librarianship, Vol.35, No.4, pp.324-331.

Yellin, J. (2011, August 1). "Week 7, Thing 13: LibraryThing", Cam23 2.0, available at http://cam23things.blogspot.co.uk/2011/08/week-7-thing-13-librarything.html (Accessed 23 July 2012) 